\title{
Research on Construction Technology for Prefabricated Stone Curtain Wall Base Keel
}

\author{
Luo Zhenglin, Zhang Haibin \\ China Construction Shenzhen Decoration Co., Ltd, Shenzhen, China \\ Email address: \\ luozlluozl@qq.com (Luo Zhenglin), zhbinyx@163.com (Zhang Haibin)
}

\section{To cite this article:}

Luo Zhenglin, Zhang Haibin. Research on Construction Technology for Prefabricated Stone Curtain Wall Base Keel. Engineering and Applied Sciences. Vol. 5, No. 6, 2020, pp. 133-148. doi: 10.11648/j.eas.20200506.15

Received: October 25, 2020; Accepted: November 20, 2020; Published: December 22, 2020

\begin{abstract}
For outer wall maintenance, the stone curtain walls are arranged on the edge of the construction accesses. There are many cross operations and high risks of construction safety. The disadvantages includes limited construction period, site constraints, local weather conditions, pedestrians and trucks. In case of construction with traditional methods, it will be necessary to close the on-site accesses most of the time, which hinders mobilization of the materials and cross-operation of other organizations and makes construction impossible in rainy days. In addition, there is high safety risk, and the work efficiency and construction period will be greatly affected. In order to ensure safety and the construction period, prefabricated base keels were planned for construction based on the site investigation and analysis. These keels were transported and installed intensively in different periods of time, so that the safety factor was significantly increased and the work efficiency was met. After prefabricated base keels were used for project construction, the stone base keels were completed successfully as scheduled. In terms of the selection of measures, construction progress, and quality, this project has won unanimous praise from the Owner and all parties. After the acceptance of the project, the stone base keels were determined as an excellent subdivisional work.
\end{abstract}

Keywords: Safety Risk, Prefabricated Type, Integral Hoisting

\section{Profit Profile}

The Office and Business Complex of Qinghai Rural Credit Cooperative and Qinghai Xining Rural Commercial Bank Co., Ltd. is located at No. 79 Haiyan Road, Haihu New District, Xining City, with a parcel area of $20,634.54 \mathrm{~m}^{2}$. The land is for commercial finance. Its overall floorage is $137,901.86 \mathrm{~m}^{2}$, including $93,434.84 \mathrm{~m}^{2}$ above the ground and $44,467.02 \mathrm{~m}^{2}$ under the ground. This Complex mainly includes $1 \#$ tower and podium building, 2\# tower, $3 \#$ tower and podium building, and $4 \#$ tower. The curtain wall height is $64.6 \mathrm{~m}$ for $1 \#$ tower, $100.2 \mathrm{~m}$ for $2 \#$ tower, $51.9 \mathrm{~m}$ for $3 \#$ tower, and $66.3 \mathrm{~m}$ for 4 \#tower. The main curtain wall systems include glass curtain walls, stone curtain walls, aluminum-plate curtain walls, aluminum-plate canopies, aluminum alloy doors \& windows, glass daylight roofs and so on. The gross area of the curtain walls is about $78,000 \mathrm{~m}^{2}$.

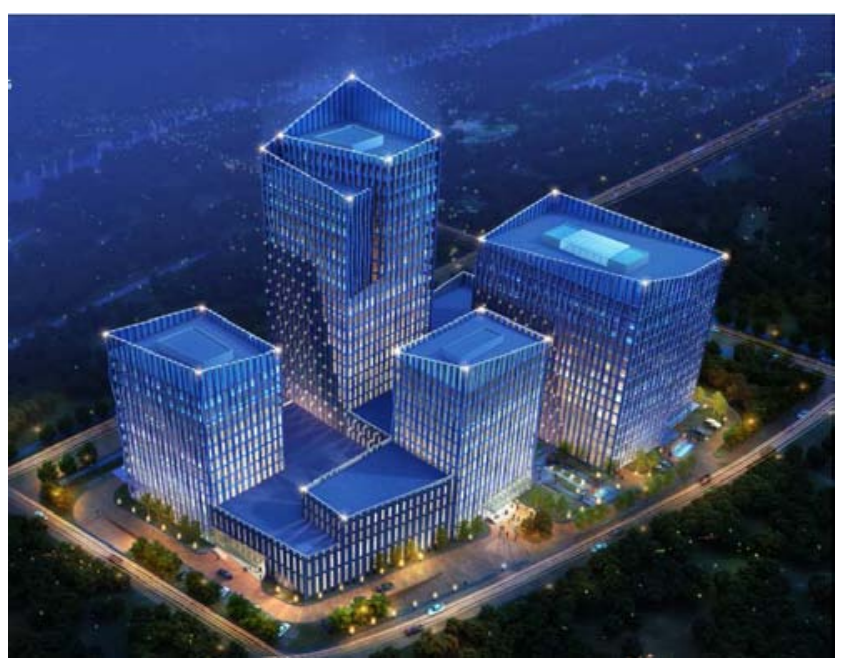

Figure 1. Overall Project Effect. 


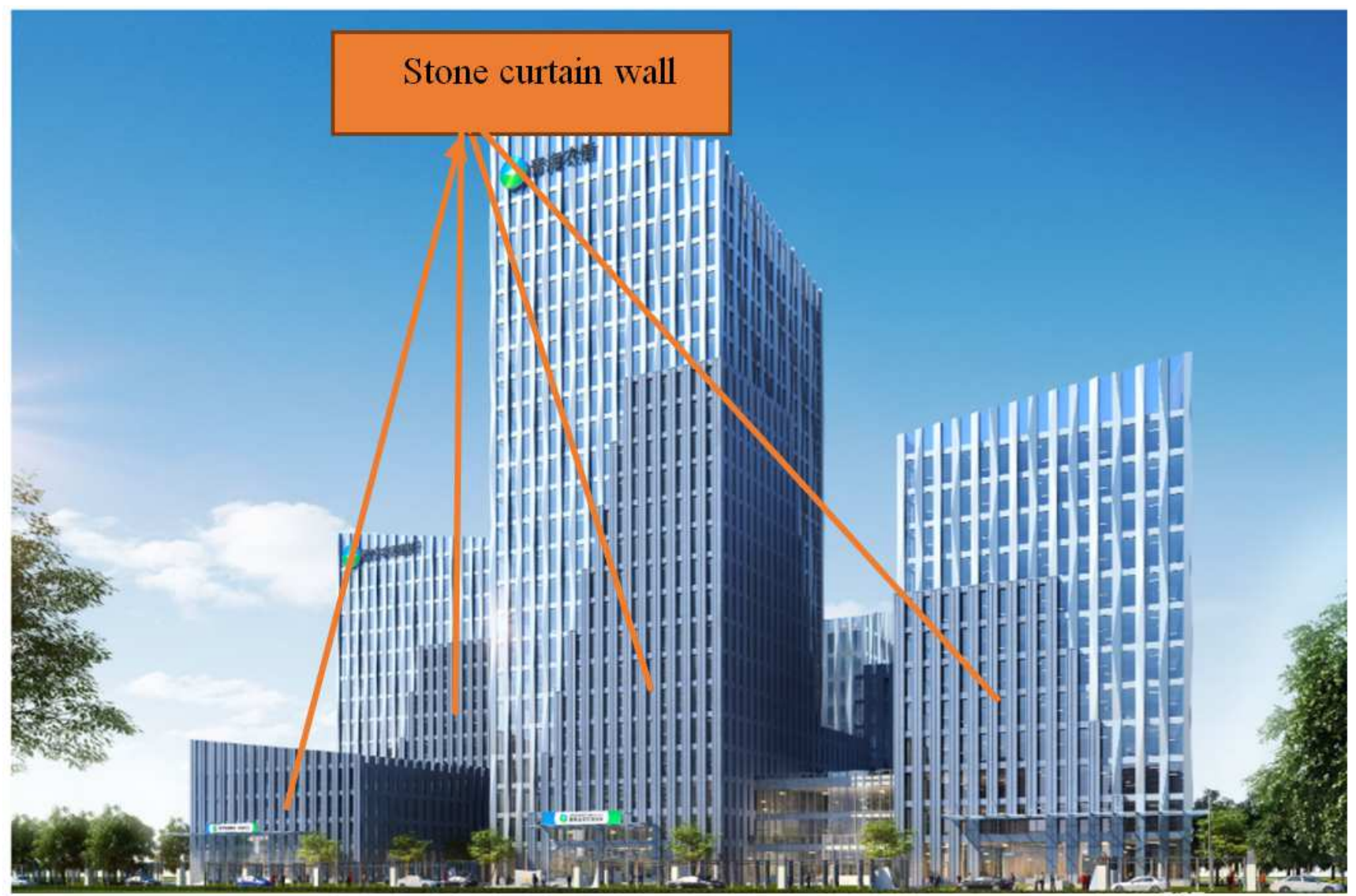

Figure 2. Schematic Diagram of the Distribution of Stone Curtain Walls.

\section{Technical Features of Project}

This technical prototype of prefabricated base keel is a frame-type stone curtain wall system for construction of the stone curtain wall base keel, which plays an important role in construction period, construction quality, safety assurance, cross operation, and construction convenience [1]. It has the following features:

(1) The prefabricated base keel can be processed indoors or outdoors and formed in one step. Its welding method changes to vertical welding from overhead welding, which facilitates the welding operation and ensures the welding quality. In addition, its construction is not affected by the climate and the conditions on the construction site;

(2) It is easy to control quality of the prefabricated base keels in welding inspection, anti-rust treatment and other processing procedures;

(3) The prefabricated base keel can be deployed according to the conditions of the on-site working face to avoid cross operation and improve safety assurance. Also, it can be installed quickly to shorten the time for on-site working face and facilitate management;

(4) When installing the prefabricated base keel, it can be welded on the connecting parts directly, which reduces the welding workload on site, shorten the time for anti-rust treatment, and correspondingly reduce the time for measures taken during installation and use;

(5) If the prefabricated base keels are used, they will be transported to the bottom of the construction location on site in the form of semi-finished products and installed by using mobile hoisting equipment. Compared with the frame type, it is transported more easily without need to use elevators for transportation, which provide convenience for transportation related to other working face [2];

(6) The prefabricated base keel is processed with a fixing falsework which is equipped with a deformation control cassette to prevent the main and secondary keels from being deformed due to excessive welding workload. The fixed box is provided for the secondary keel so that the distance between the main and secondary keels and their deformation are controlled effectively;

(7) Structural models of prefabricated base keel:

In the installation of stone curtain walls of this project, there are three structural models for installation of prefabricated base keel, including one kind of common stone stand column and two kinds of corner columns. The main prefabricated base keel used in this project is shown in Figure 3 and corner columns are shown in Figures 4 and 5 (as shown below). 


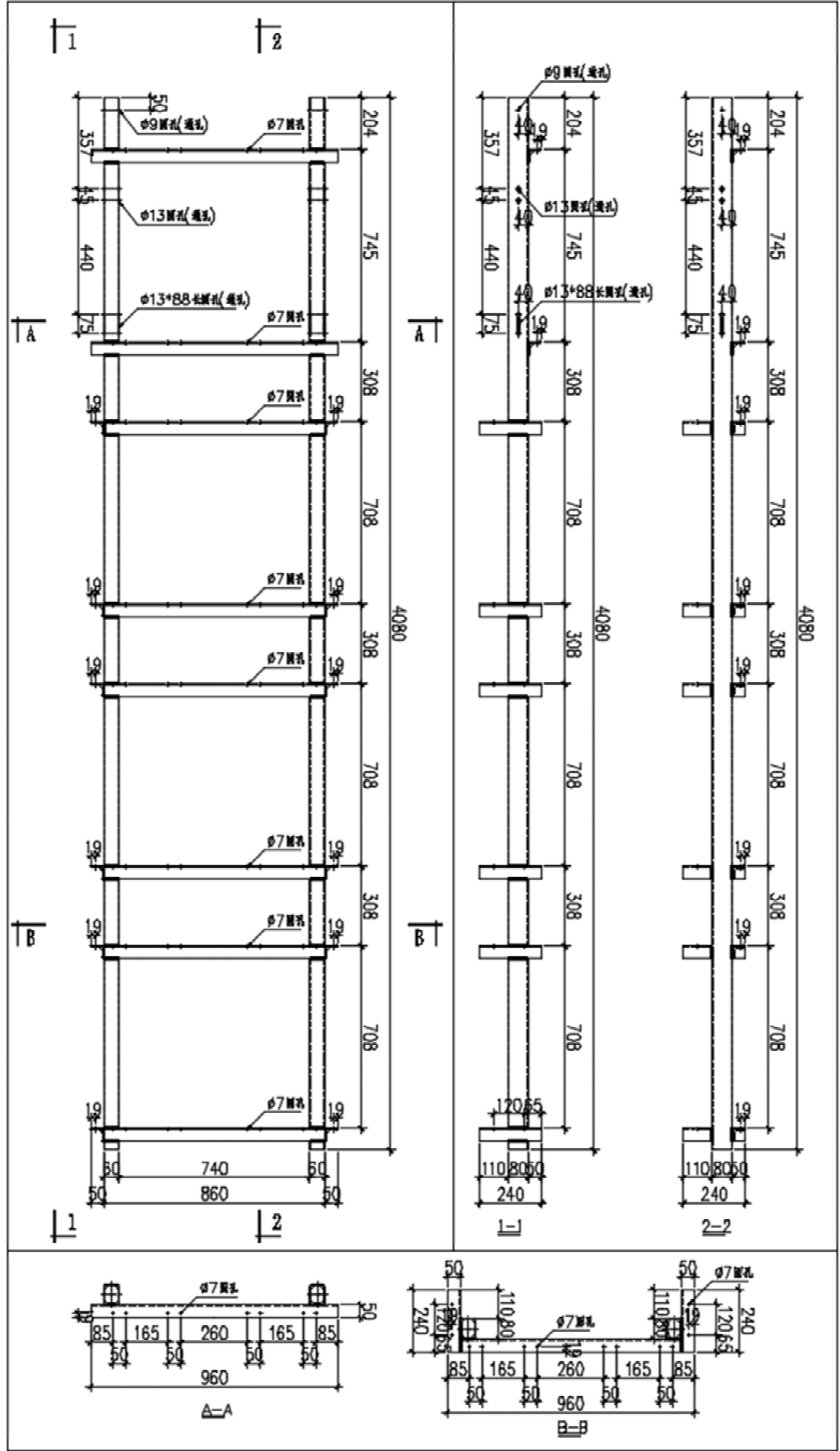

Figure 3. Schematic diagram of prefabricated keel (1). 


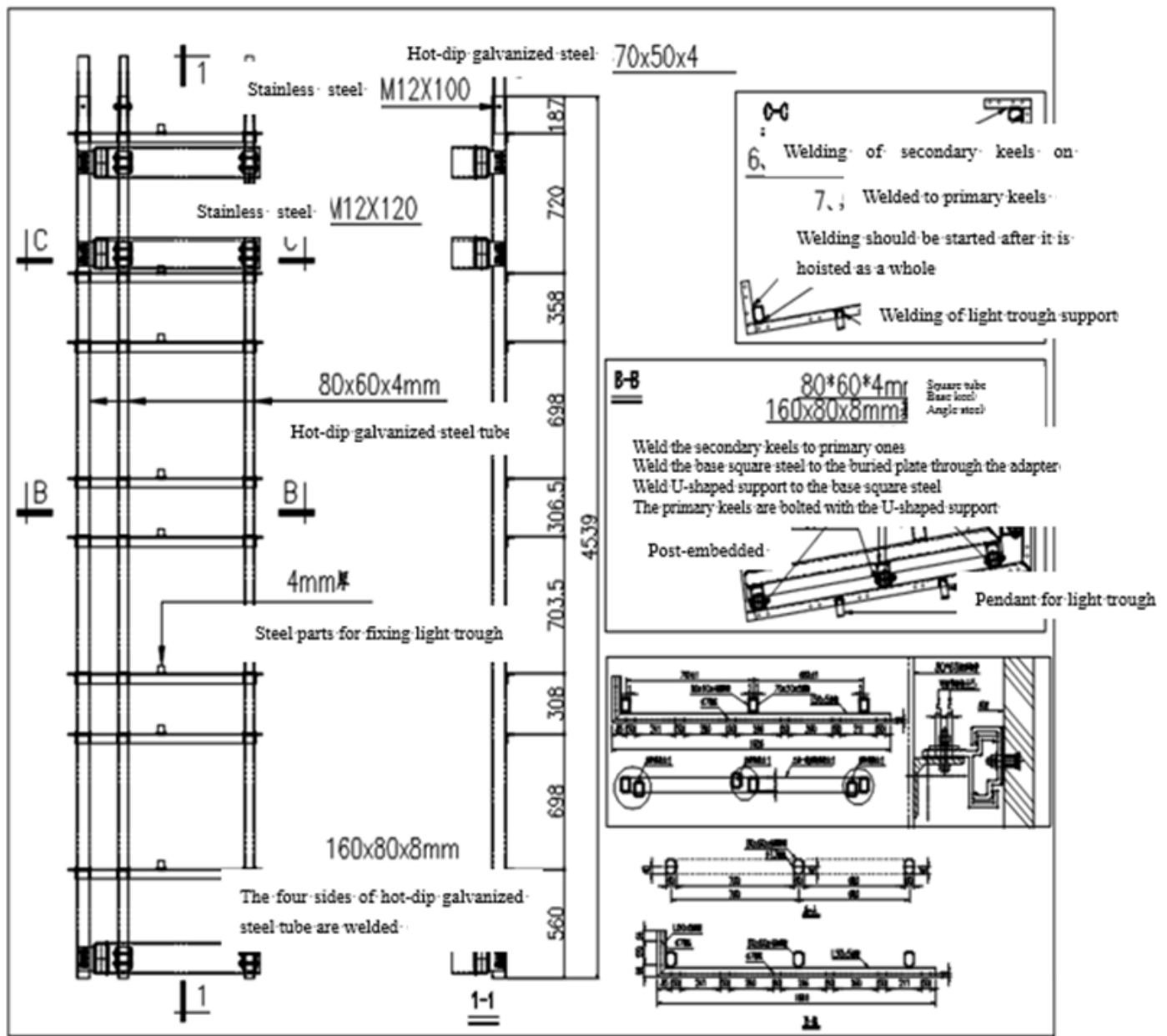

Figure 4. Schematic diagram of prefabricated keel (2).
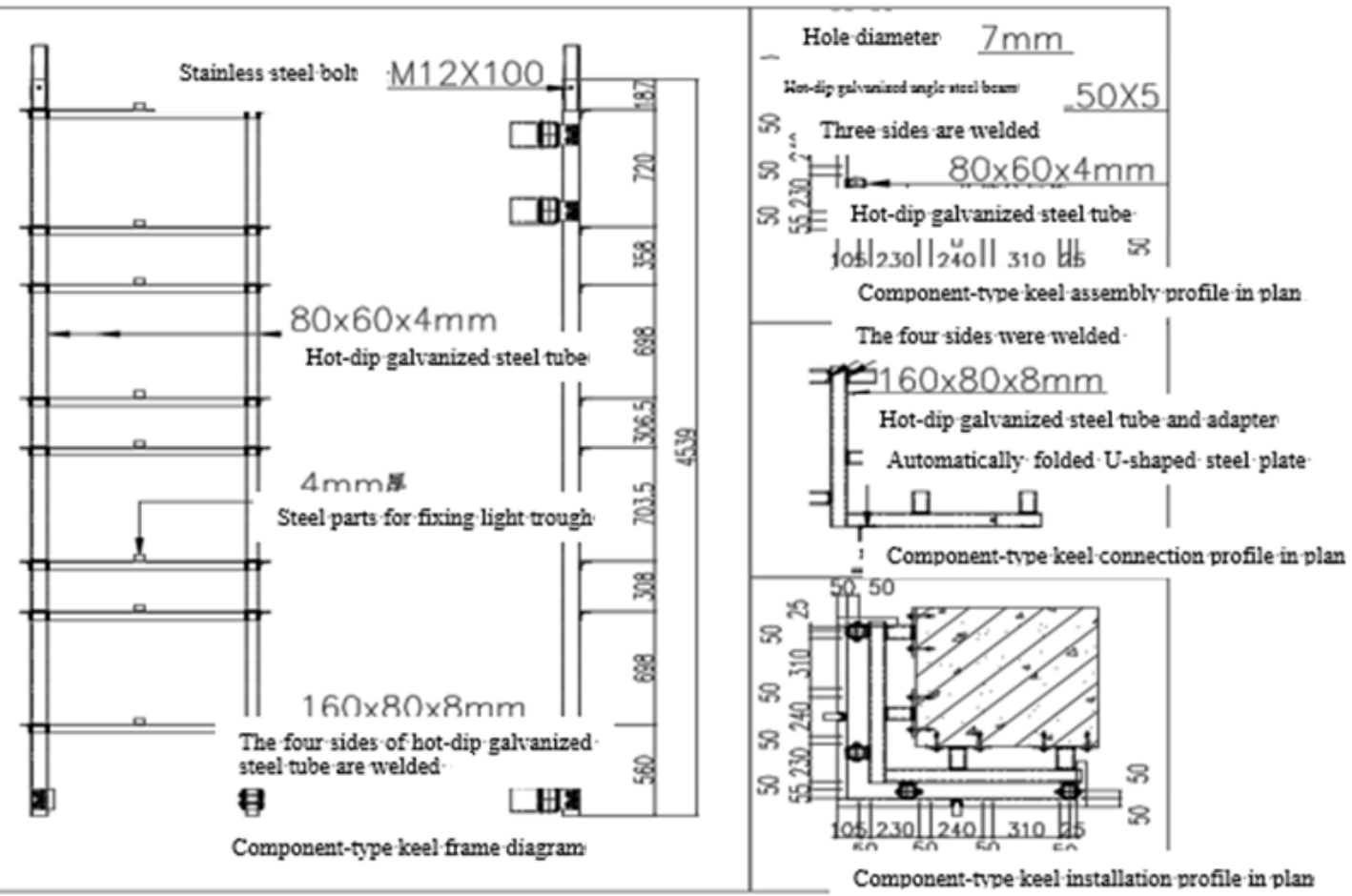

Figure 5. Schematic diagram of prefabricated keel (3). 
(8) Fabrication of falsework:

The falsework should be fabricated according to the processing drawing of the prefabricated type, and the specification and size should be determined to ensure the finished prefabricated components meet the requirements of the processing drawing and control the deformation of the components [3].

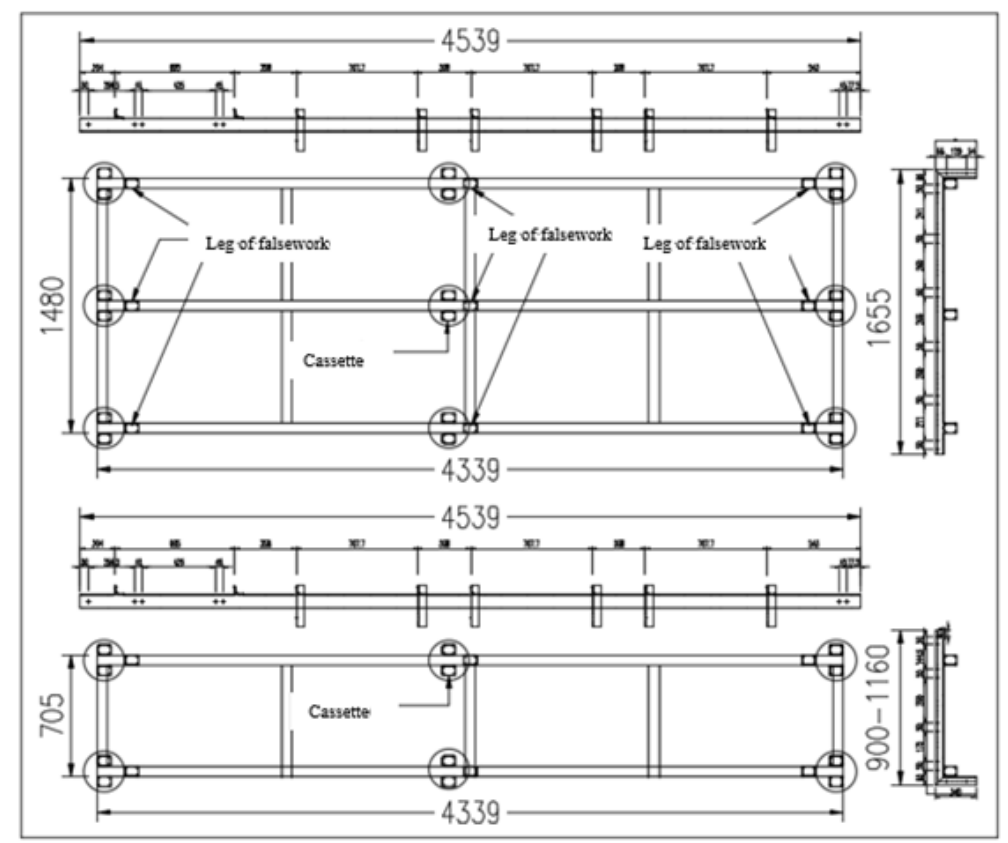

Figure 6. Schematic diagram of falsework.

\section{Construction Processes and Operation Points of Prefabricated Stone Keels}

\subsection{Construction Processes of Prefabricated Stone Keels}

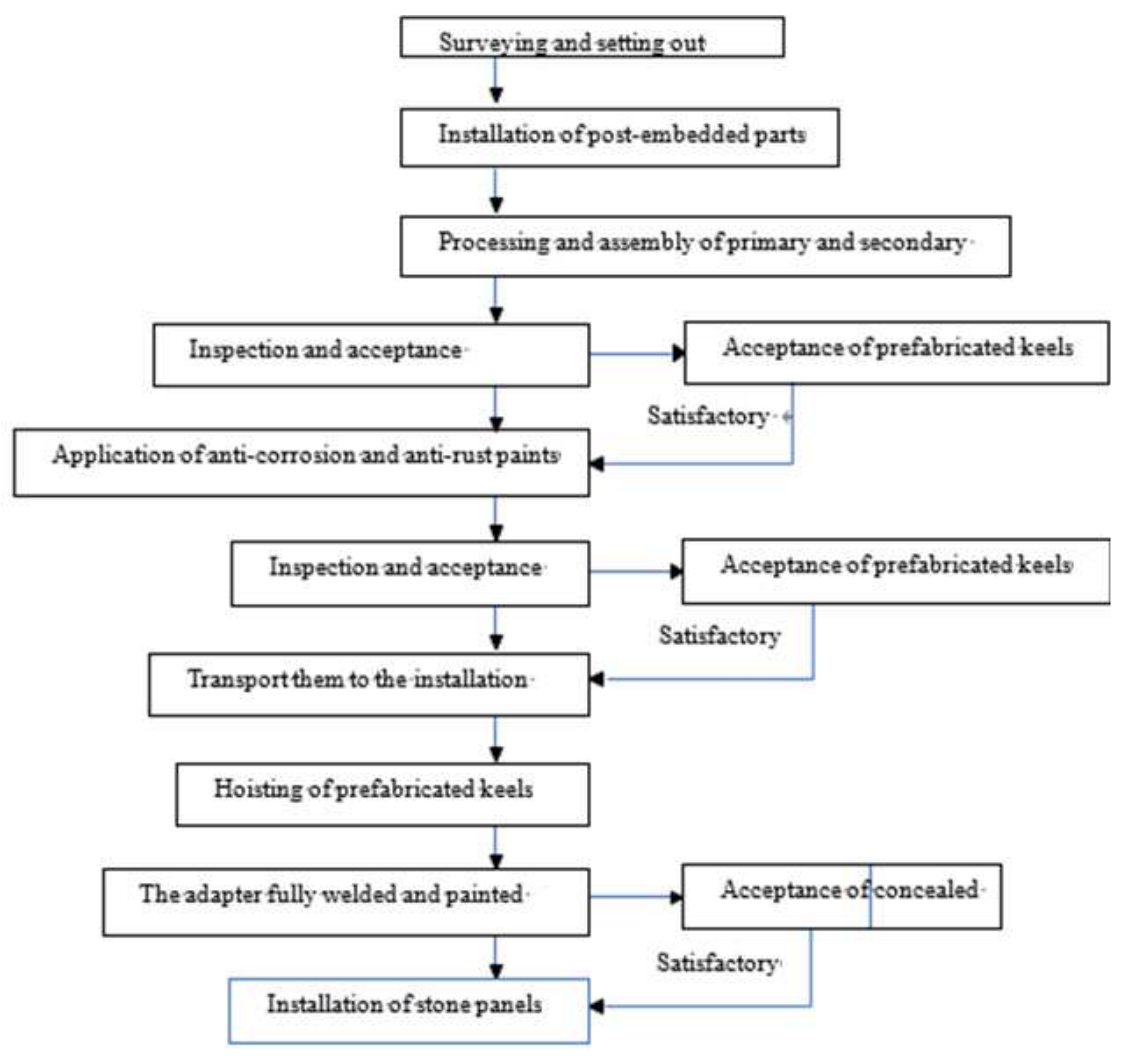

Figure 7. Construction Processes of Prefabricated stOne Keels. 


\section{Installation of base keel}

\subsection{Operation Points}

The prefabricated base keel is similar to the original frame in terms of the process before the fabrication and installation. This paper analyzes the process of the prefabricated base keel in terms of its drawing, processing and installation [4];

\subsubsection{Early-Stage Preparation}

1. The measures have been taken and accepted;

2. Machine tools include cutting machine, electric welding machine, bench drill, steel wire, total station, level, lead weight, self-made flat car;

3. Materials include steels, welding rods, anti-rust paint, and color separation paper, etc.;

4. Prepare the processing drawings for the prefabricated base keels as required and fabricate the falsework based on the processing drawings.

\subsubsection{Processing of Primary and Secondary Prefabricated Base Keels}

The primary and secondary keels should be processed according to the processing drawings. A cutting machine should be cut materials (Where appropriate, a heavy-duty punch can be used to cut and perforate the angle steels). Where the primary keels are hung with two methods, the round hole with a diameter of $13 \mathrm{~mm}$ should be formed in punching for the first time and the vertical strip-shaped hole should be formed in punching for the second time [5]. The vertical strip-shaped holes are used for the lower end of the first floor. In the processing drawing, the secondary keel should be perforated according to the spacing of holes for back-bolted aluminum pendants which should be subject to the requirements for stone margin;

The primary keels are made of $80 * 60 * 4 \mathrm{~mm}$ hot-dip galvanized steel square tubes, while the secondary keels are made of L $50 * 5 \mathrm{~mm}$ hot-dip galvanized angle steels, and the adapters are made of hot-dip galvanized angle steel supports with dimension of $\mathrm{L} 110 * 70 * 8 \mathrm{~mm}$. $160 * 80 * 8 \mathrm{~mm}$ hot-dip galvanized steel square tube and U-shaped necks should be provided for base support of corner columns;

Processing of primary keels:

$\mathrm{H}$ refers to the storey height. When $\mathrm{H}$ is $4.5 \mathrm{~m}, 4.2 \mathrm{~m}$ and $4.1 \mathrm{~m}$, the processing length should be $4.48 \mathrm{~m}, 4.18 \mathrm{~m}$ and $4.08 \mathrm{~m}$, respectively, in which $20 \mathrm{~mm}$ of settlement gap should be reserved [6]. The vertical strip-shaped holes should be formed for installation of adaptors at the lower end of the first stand column on the first floor and at the lower end of the interlayer;

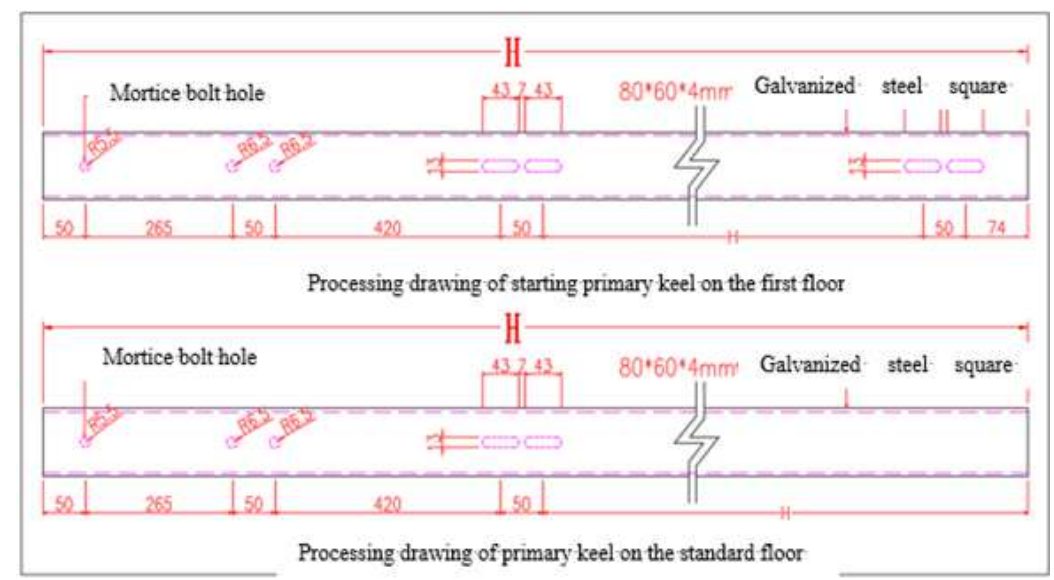

Figure 8. Processing drawing of starting primary keels.

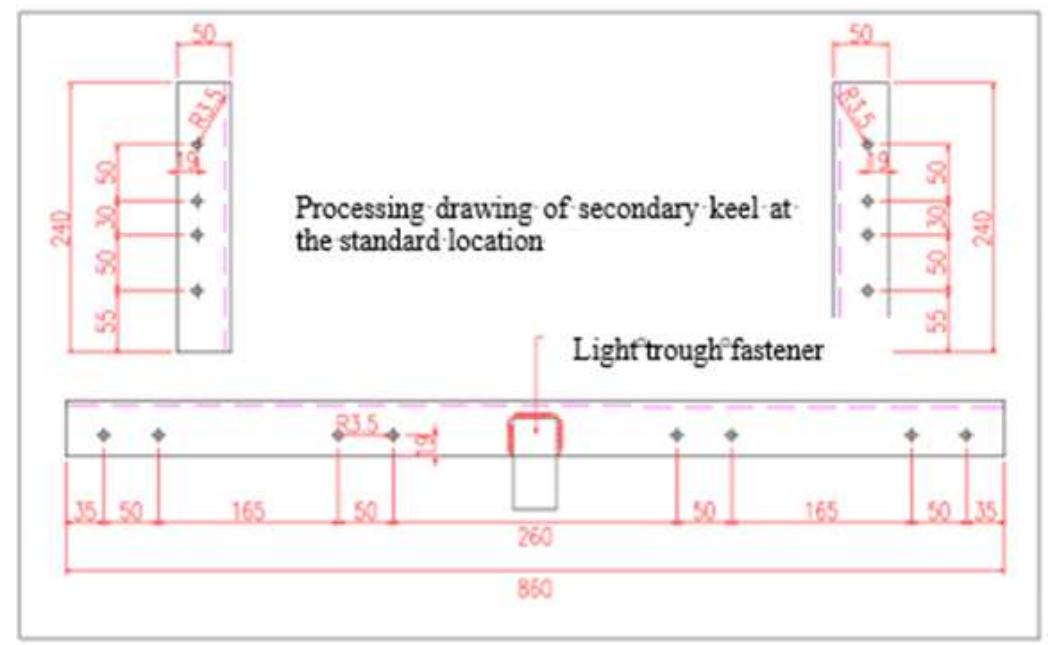

Figure 9. Processing drawing of secondary keel at the standard locatiob. 


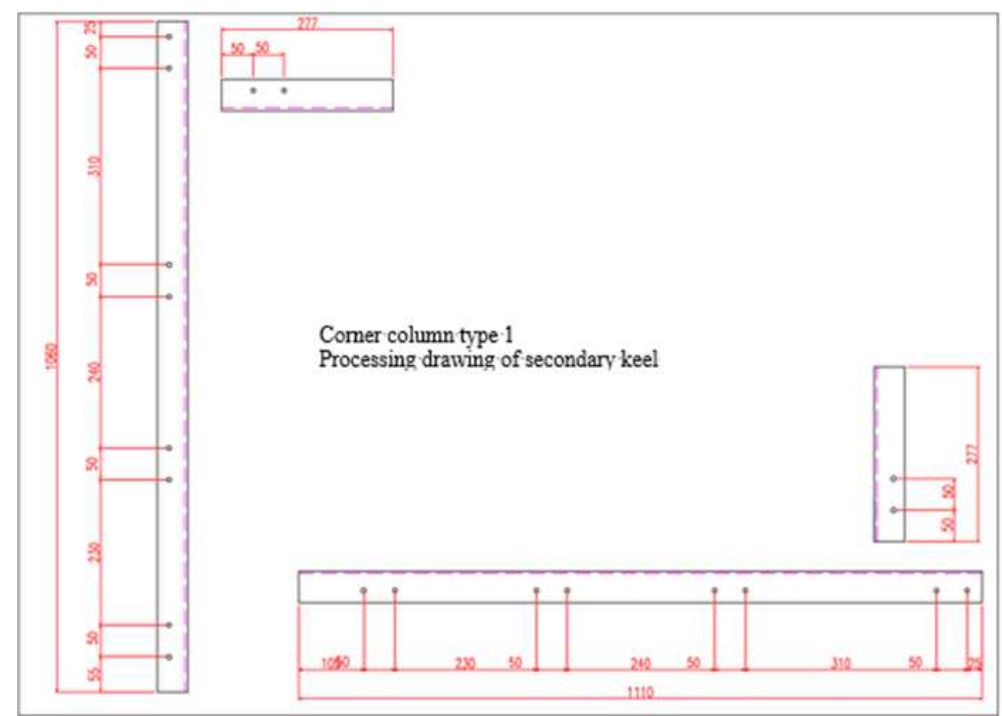

Figure 10. Corner column type 1 Processing drawing of secondary keel.

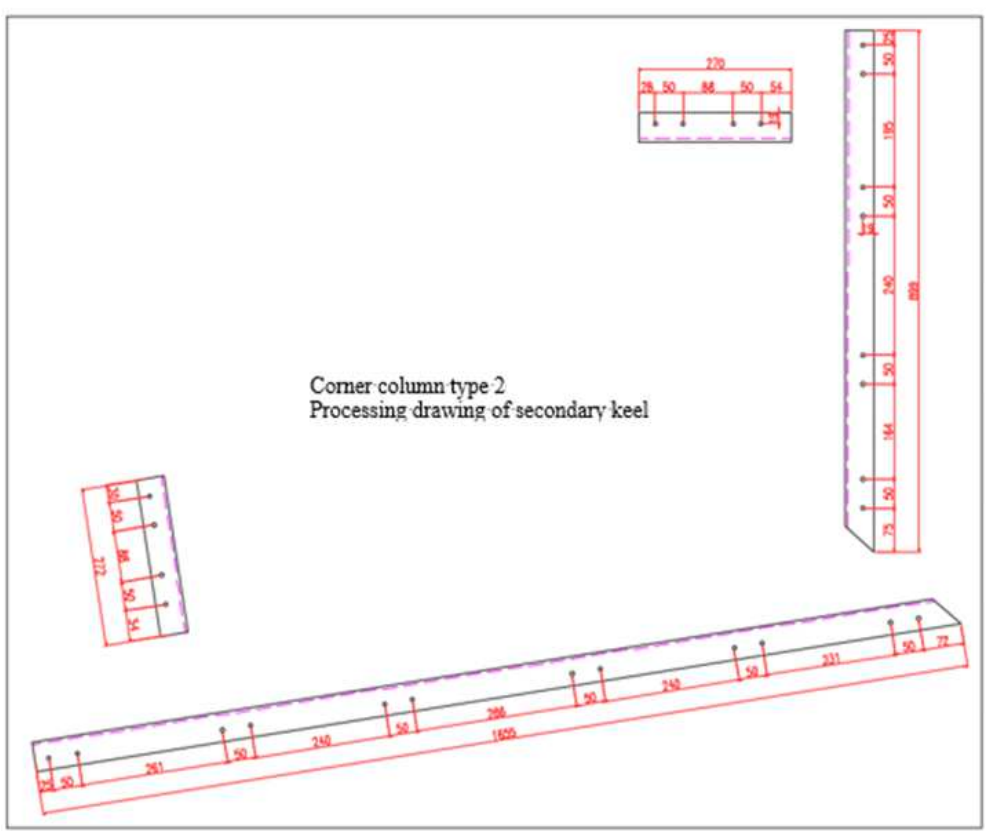

Figure 11. Corner column type 2 Processing drawing of secondary keel.

\section{i. Assembly of Secondary Keels}

The finished secondary keels should be assembled

When assembling the secondary keels at the standard location, welding should not be allowed inside. Otherwise, it will conflict with the primary keels in assembly.

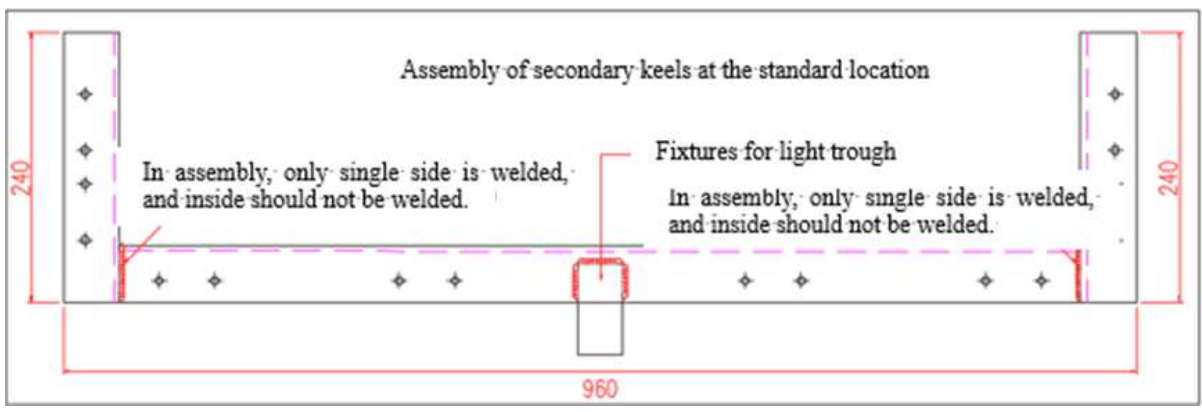

Figure 12. Assembly of secondary keels at the standard location in assembly, only single side is welded, and inside should not be welded, fixtures for light trough. 


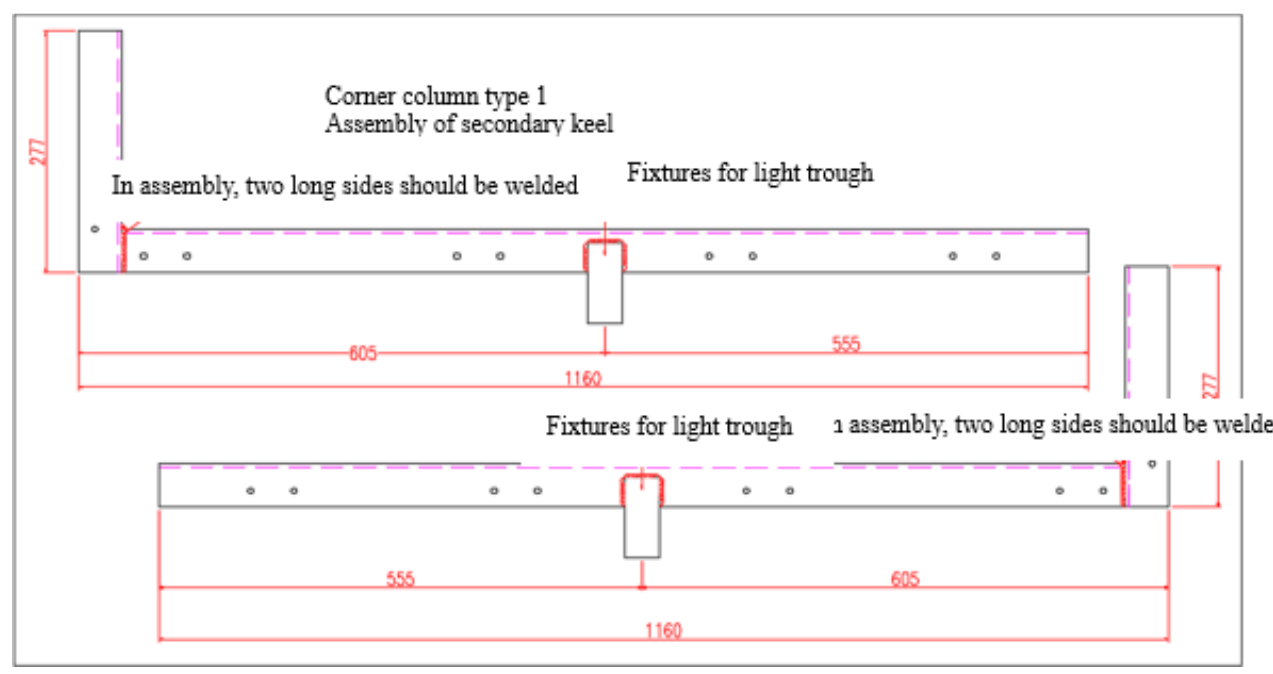

Figure 13. Corner column type 1 Assembky of secondary keel In assembly, two long sides should be welded.

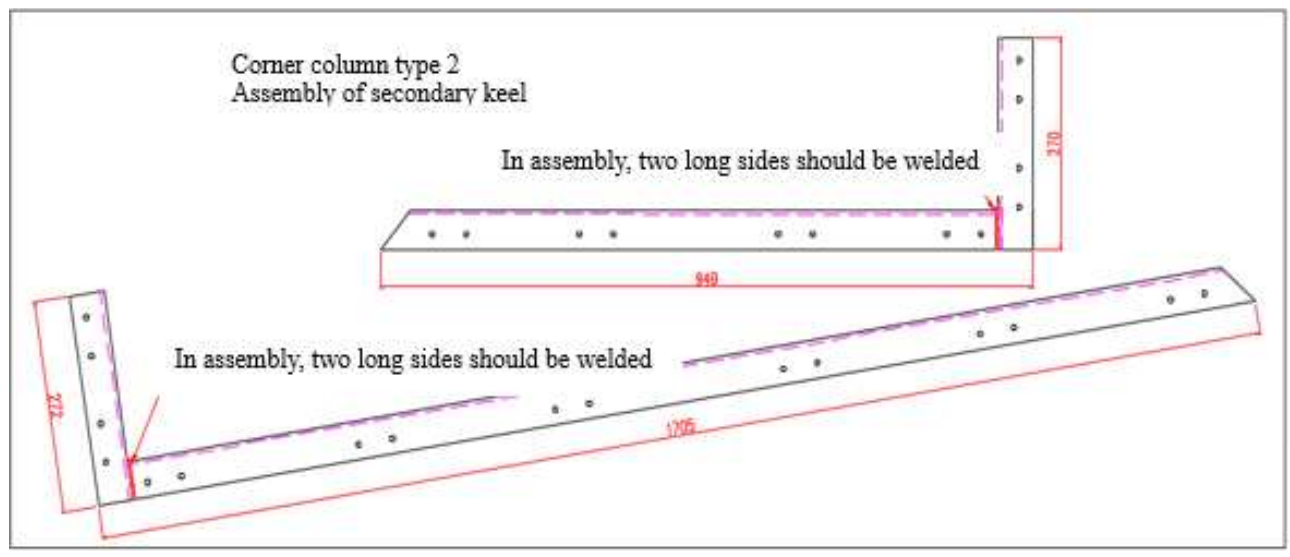

Figure 14. Corner column type 2 Assembly of secondary keel.

\section{ii. Processing and Assembly of Corner Column Support}

In assembly of supports, the four sides should be welded.

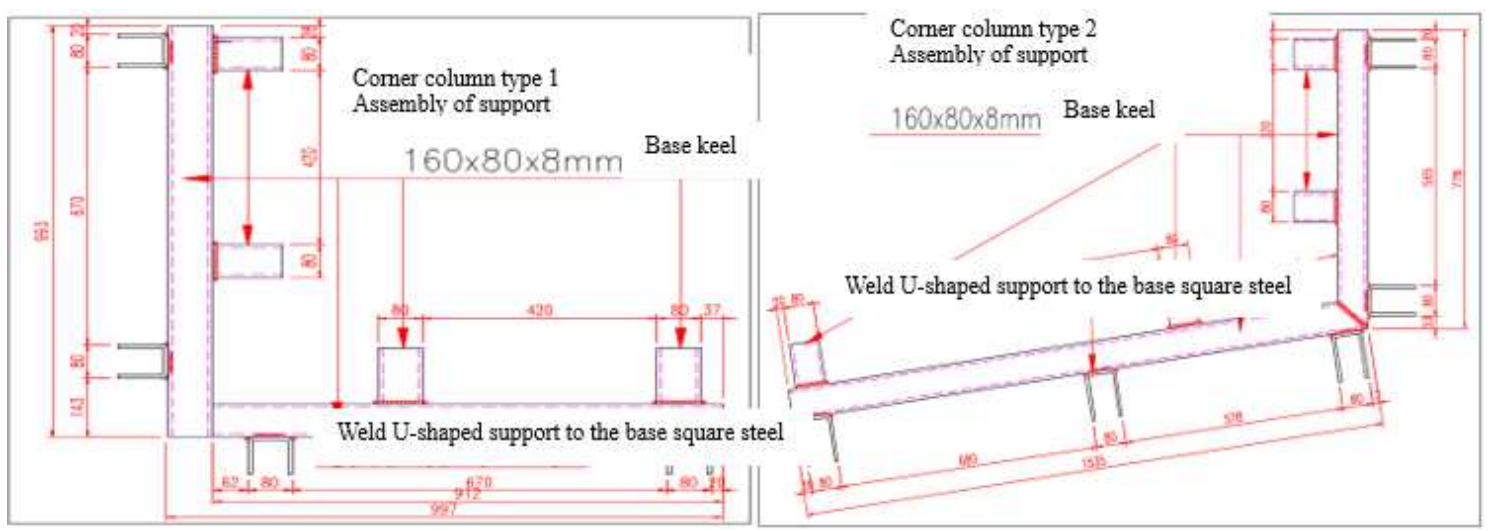

Figure 15. Corner column type 1 Assembly of support and Corner column type 2 Assembly of support.

iii. Assembly of Prefabricated Base Keel

According to the processing drawing, the faslework should be provided with spacers and the finished primary keel should be place and fixed on the faslework. Then, the finished secondary keel should be placed and spot-welded on the primary keel based on the requirement for the spacing. After that, the spacing should be inspected with reference to the processing drawing. If the result is satisfactory, full-length welding should be started, and the welding position should be in line with the drawings. The fully welding length should not be small than the steel thickness or exceed 1.5 times of that. Full-length welding should be performed at a spacing to prevent the deformation of primary keel caused by high welding temperature [7]. At the end of full-length welding, the 
components shall be unloaded to the designated area and stacked in an orderly manner. After being cooled, these components should be rechecked, and those that have been deformed should be corrected. Acceptance should be started after these components meet the requirements [8].

Control requirements for processing specification:

1. In this project, the primary keels are steel square tubes with dimension of $80 * 60 * 4 \mathrm{~mm}$ and the mortices are made of steel square tubes with dimension of $70 * 50 * 5 \mathrm{~mm}$. The unilateral mortice can be adjusted to $2 \mathrm{~mm}$, and the left and right spacing and flatness \pm deviation of the prefabricated base construction must be less than $1 \mathrm{~mm}$;

2. The inlet and outlet positions of the back-bolted aluminum alloy pendants for the stones can be adjusted within $5 \mathrm{~mm}$, and the curvature tolerance of the steel square tubes and stand columns must not be greater than $4 \mathrm{~mm}$ [9].

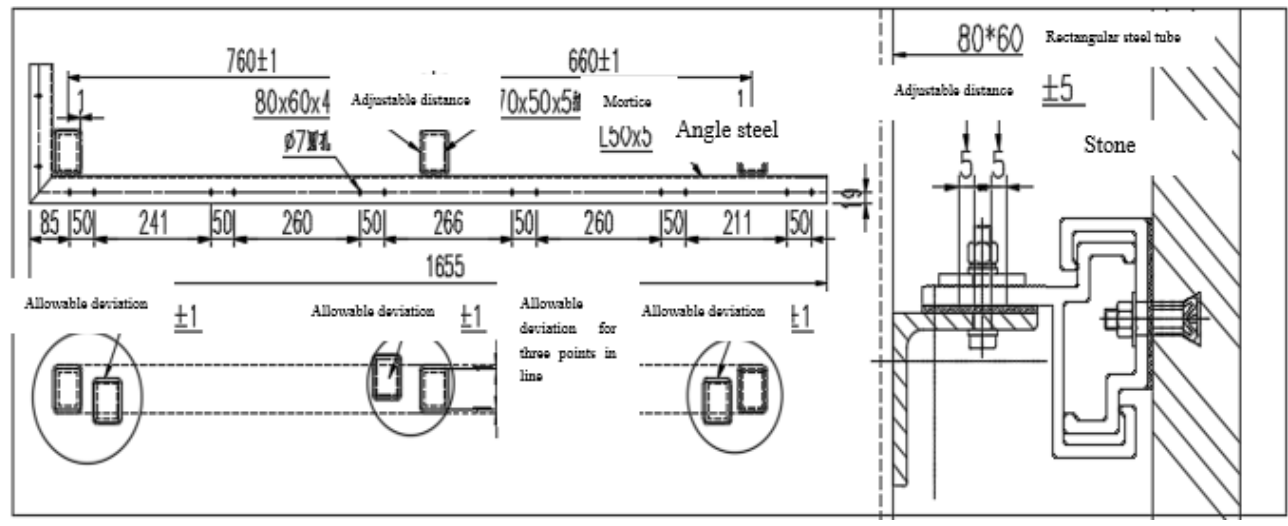

Figure 16. Drawing of primary keel.

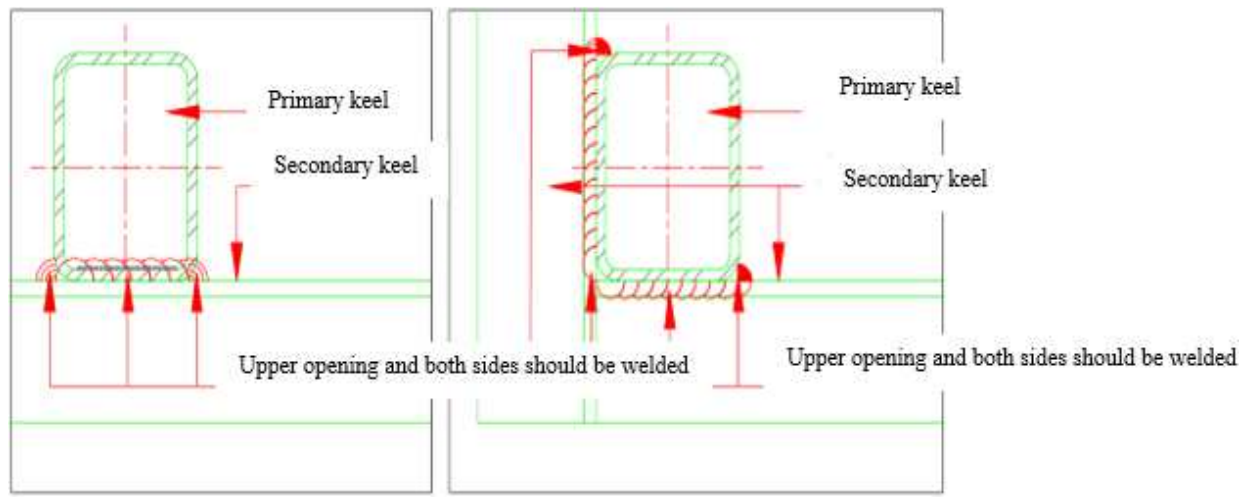

Figure 17. Welding requirements for prefabricated primary and secondary keels in assembly.

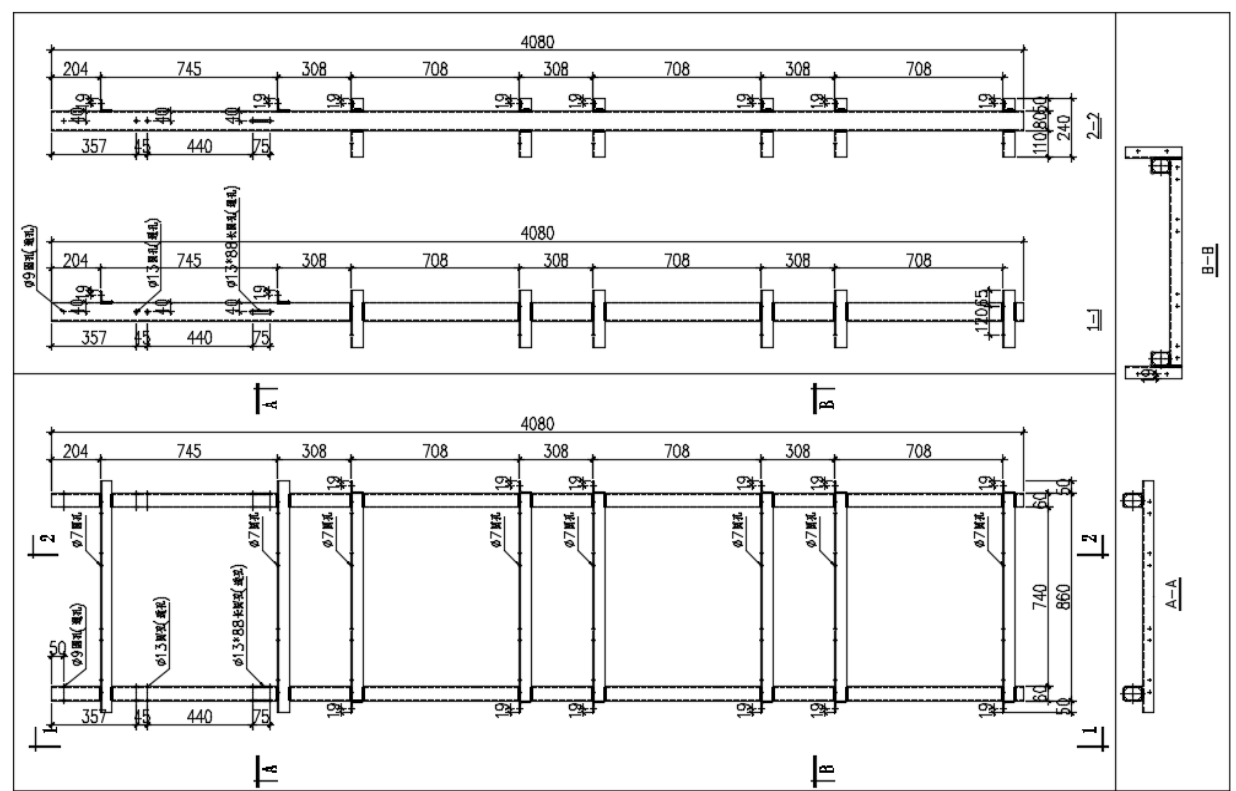

Figure 18. Assembly of prefabricated keels at the standard location. 


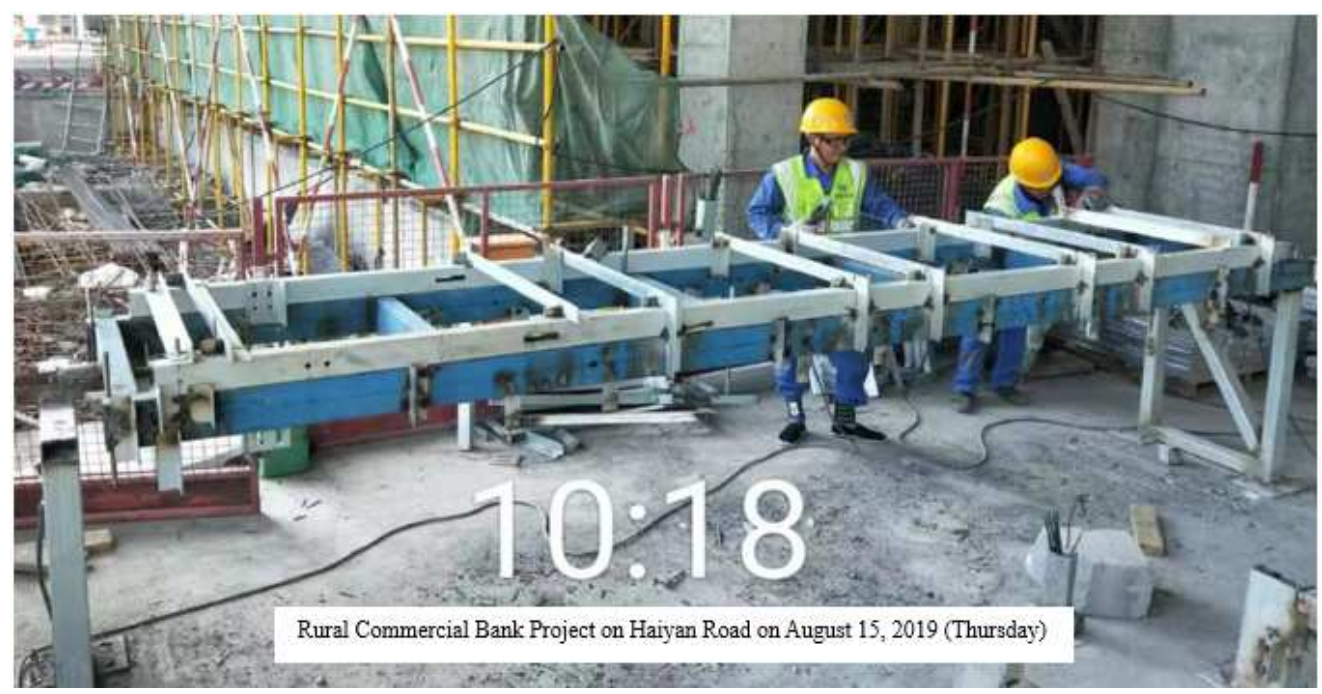

Figure 19. Project site: Rural Commercial Bank Project on Haiyan Road on August 15, 2019 (Thursday).

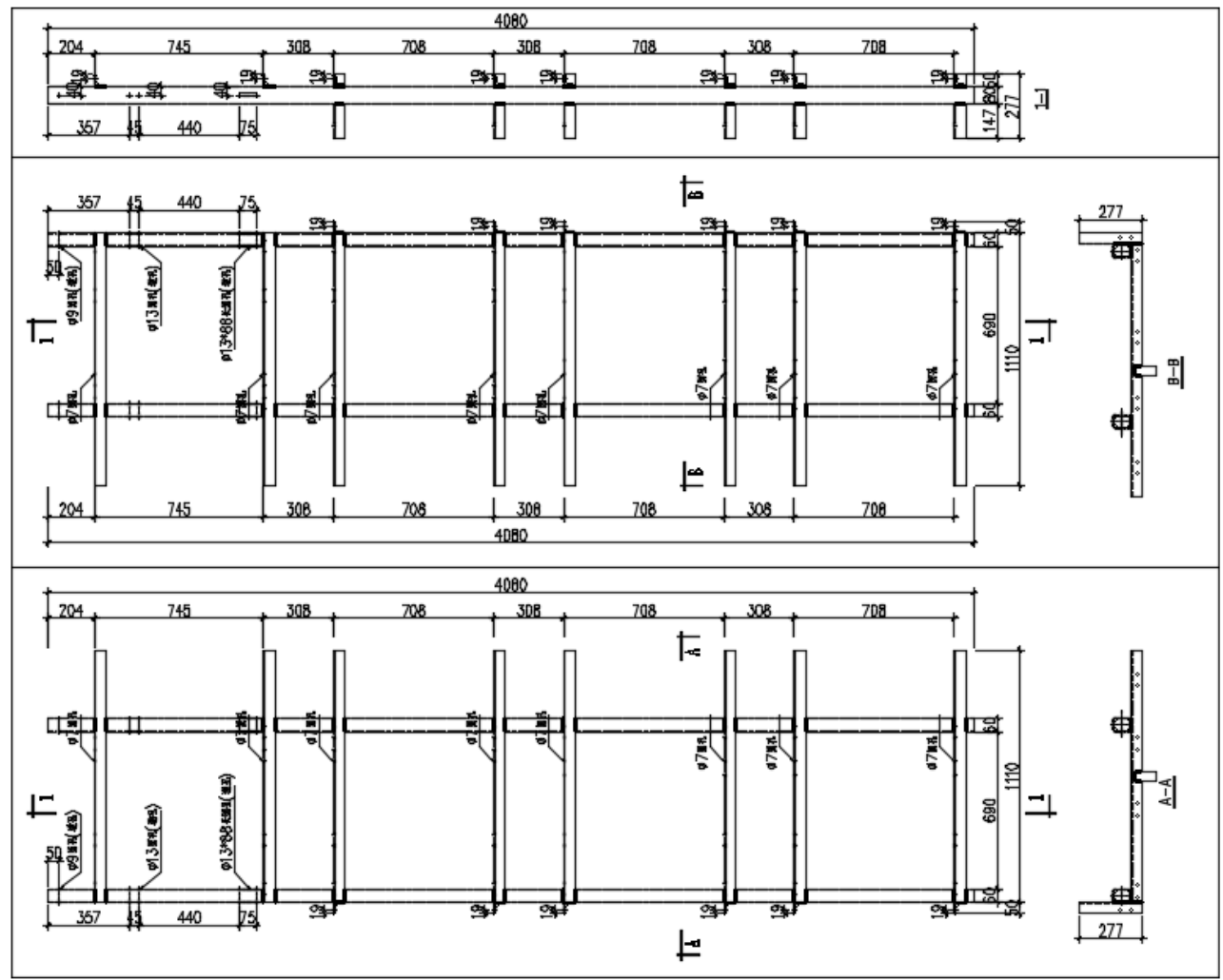

Figure 20. Assembly of prefabricated keels for corner column 1.

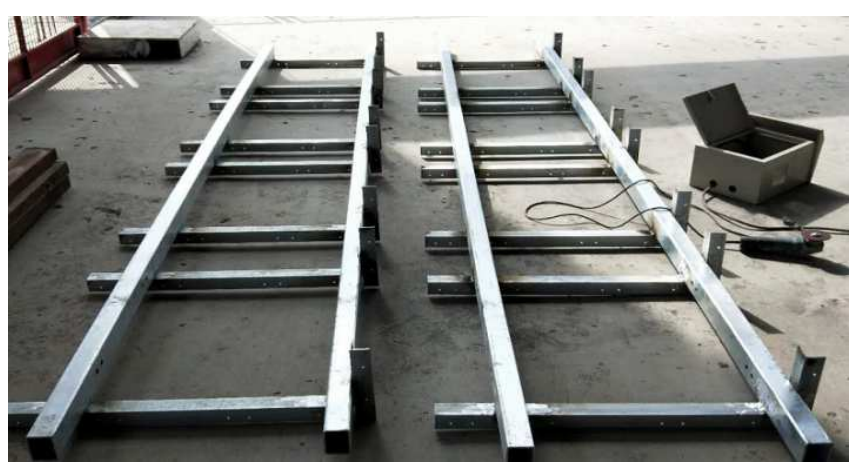

Figure 21. Photo of construction site. 


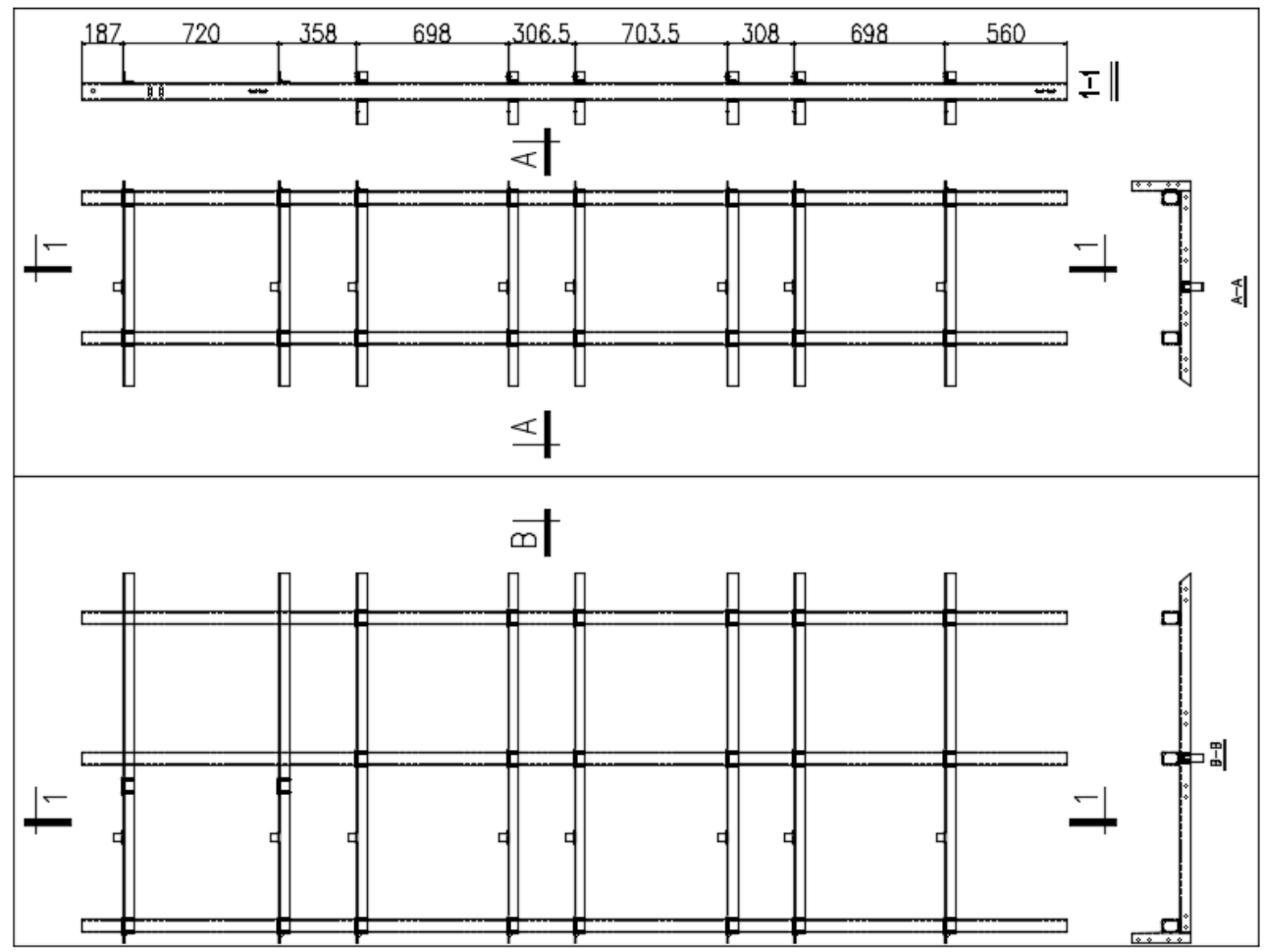

Figure 22. Assembly of prefabricated keels for corner column 2.

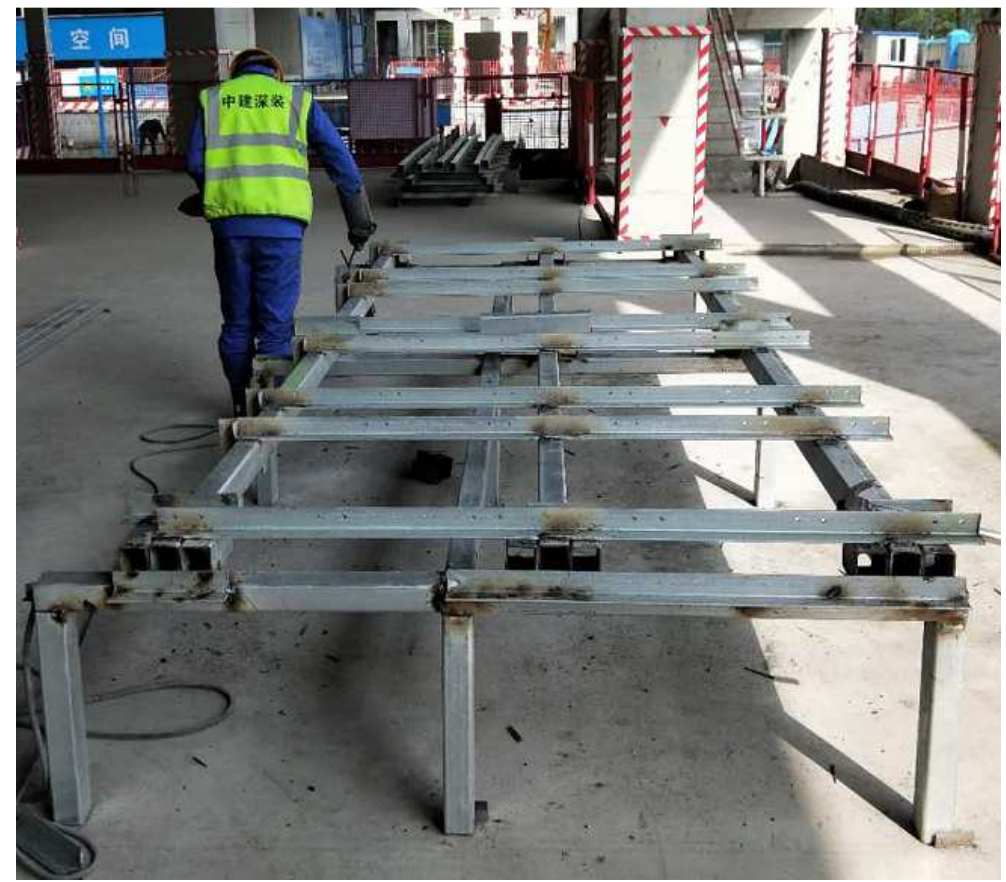

Figure 23. Photo of construction site.

\subsubsection{Inspection and Acceptance}

Check the keel specification, welding quality, the flatness primary and secondary keels and the spacing between them, and keel deformation [10].

The inspection criterion should be subject to the control requirements for processing specification:

1. In this project, the primary keels are steel square tubes with dimension of $80 * 60 * 4 \mathrm{~mm}$ and the mortices are made of steel square tubes with dimension of $70 * 50 * 5 \mathrm{~mm}$. The unilateral mortice can be adjusted to $2 \mathrm{~mm}$, and the left and right spacing and flatness \pm deviation of the prefabricated base construction must be less than $1 \mathrm{~mm}$; (If the deviation is not controlled properly, the upper and lower mortices will not be connected during installation)

2. The inlet and outlet positions of the back-bolted aluminum alloy pendants for the stones can be adjusted within 
$5 \mathrm{~mm}$, and the curvature tolerance of the steel square tubes and stand columns must not be greater than $4 \mathrm{~mm}$. (If the deviation is not controlled properly, the facade will not be vertical and become arc-shaped when the stone is installed, or punching positions will be required to be changed)

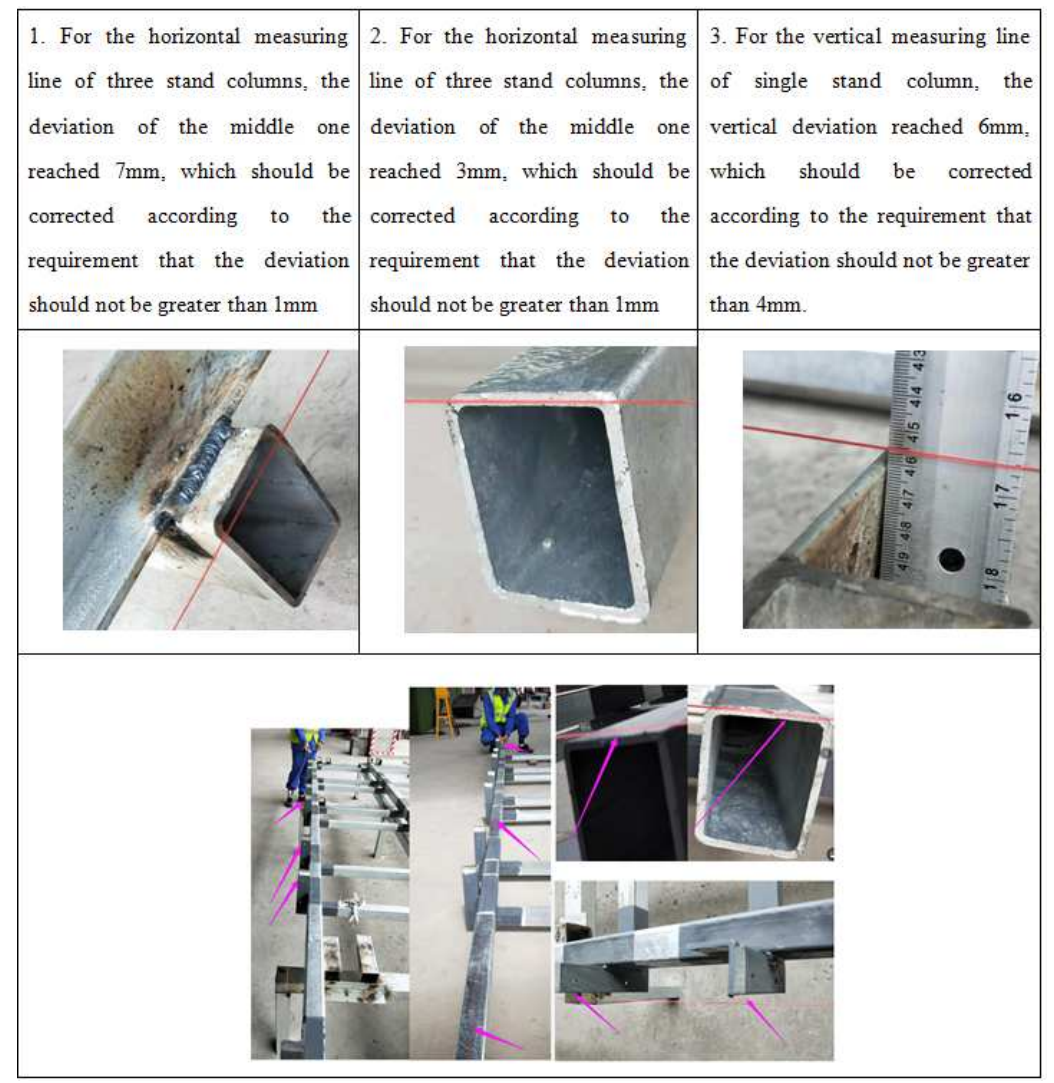

Figure 24. Checkpoints.

Suggestions: 1. Reduce the length of the long side of the mortice by $2 \mathrm{~mm}$, and change the original specification $70 * 50$ * 5mm to $68 * 50 * 5 \mathrm{~mm}$ for the steel square tubes [11];

2. Adjust the inlet and outlet positions of the aluminum pendants for the stones, and the original curvature tolerance of the primary keels should not be greater than $8 \mathrm{~mm}$ instead of $4 \mathrm{~mm}$.

\subsubsection{Correction}

If the inspection results show that the steels are deformed caused by welding operation, corrective measures shall be taken until the allowable deviation is reached;

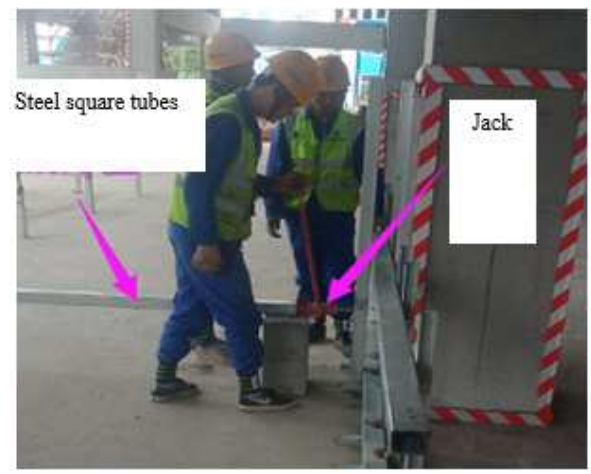

Figure 25. Photo of construction site- Correction.

\subsubsection{Anti-corrosion and Anti-rust Treatment}

\section{i. Anti-corrosion and Anti-rust Treatment}

Remove the welding slag and check the welding quality. The welds should be full without solder skips, slag inclusion, undercut, bubble, camber, excessive length of welding. Anti-rust treatment should be started after the requirements for welding quality are met. At least two anti-rust coatings should be provided, with the minimum film thickness of $110 \mu \mathrm{m}$. The edge of anti-rust treatment should be clean and tidy.

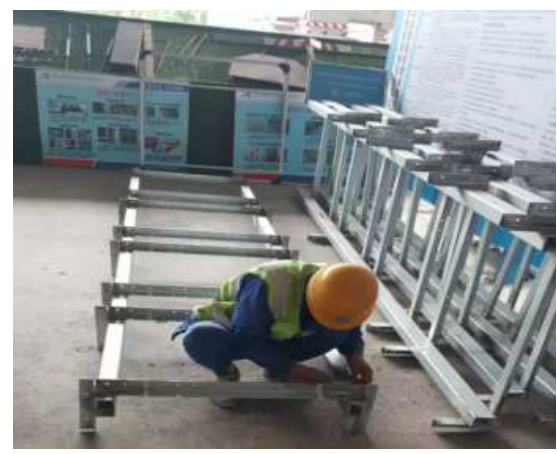

Figure 26. Anti-corrosion and Anti-rust Treatment.

ii. Acceptance of Anti-corrosion and Anti-rust Coatings Check the anti-rust paint to see whether it meets the 
requirements, including the quality of anti-rust treatment and film thickness. The welding location shall receive the anti-rust treatment in horizontal and vertical directions. The edge shall be clean. At least two anti-rust coatings should be provided, with the minimum film thickness of $110 \mu \mathrm{m}$.

Inspection criterion: visual inspection and film tester

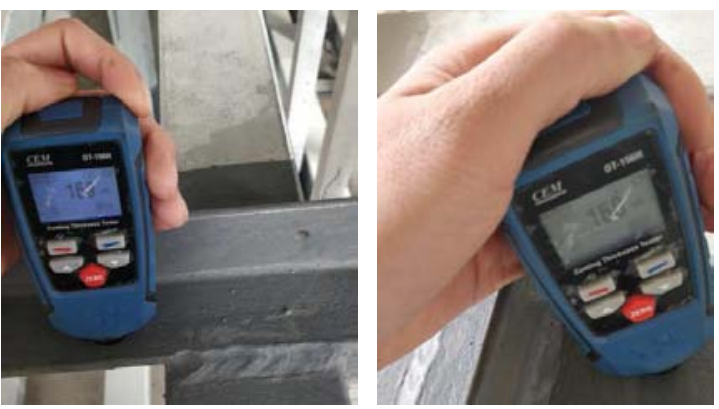

Figure 27. Film tester.
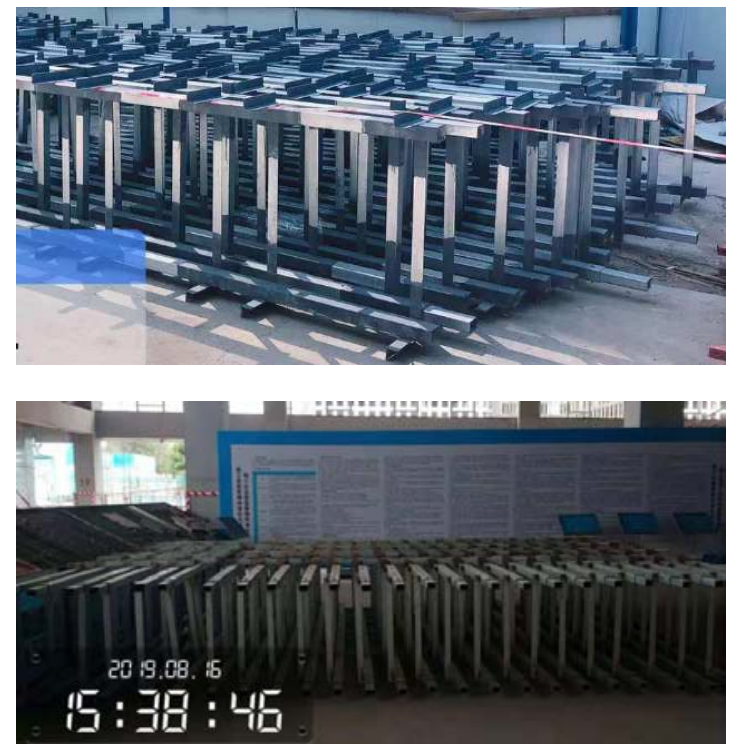

Figure 28. Acceptance of Anti-corrosion and Anti-rust Coatings.

\subsubsection{Installation of Prefabricated Products}

\section{$i$. Transportation of Prefabricated Products}

The self-made flat cart was used for transportation, and the transportation channel was cleaned before transportation. The keel at the corner column, the largest weight of the project, was $168.92 \mathrm{~kg}$ (the first layer), and the construction member weight of the standard part was $133.63 \mathrm{~kg} ; 4$ people were need to do the transportation; construction members were transported to the bottom of the installation position and stacked neatly according to the daily installation demand;

ii. Installation of Prefabricated Products

Before construction, the components were transported by 4 people to the hoisting position by self-made flat trolley. During the hoisting process, cross operation was strictly prohibited under the hoisting; during hoisting, the hanging basket was raised above the position to be installed. After the components were hoisted to the position to be installed, the hanging basket was lowered to the installation position for installation. The indoor personnel cooperated to put the lower component into the sleeve, and the upper part would be welded after the lower part was returned to its original position; the lifting strap would be removed after the welding was firm; after confirmation that the welding was firm, the verticality, flatness and elevation was checked. After correction, the hoisting system was unloaded; after the diagonal sub keel was welded, welding slag was cleared in time; Whether the weld meets the requirements was checked, and the anti-rust treatment of the weld was done in time [12].

The self-made steel hoist was used for hoisting, and 1 ton electric hoist was applied. Calculation of the maximum weight of the assembled integral steel frame: $8.14 * 4.54 * 3+(1.655+0.27) * 8=168.92 \mathrm{~kg}$; via calculation, the hoisting equipment can lift $300 \mathrm{~kg}$, meeting the hoisting requirements.

The finished construction members were welded with the embedded plate by the adapter, and the base support of $160 *$ $80 * 8 \mathrm{~mm}$ hot-dip galvanized steel square pass and U-shaped clamp groove were installed at the corner column;

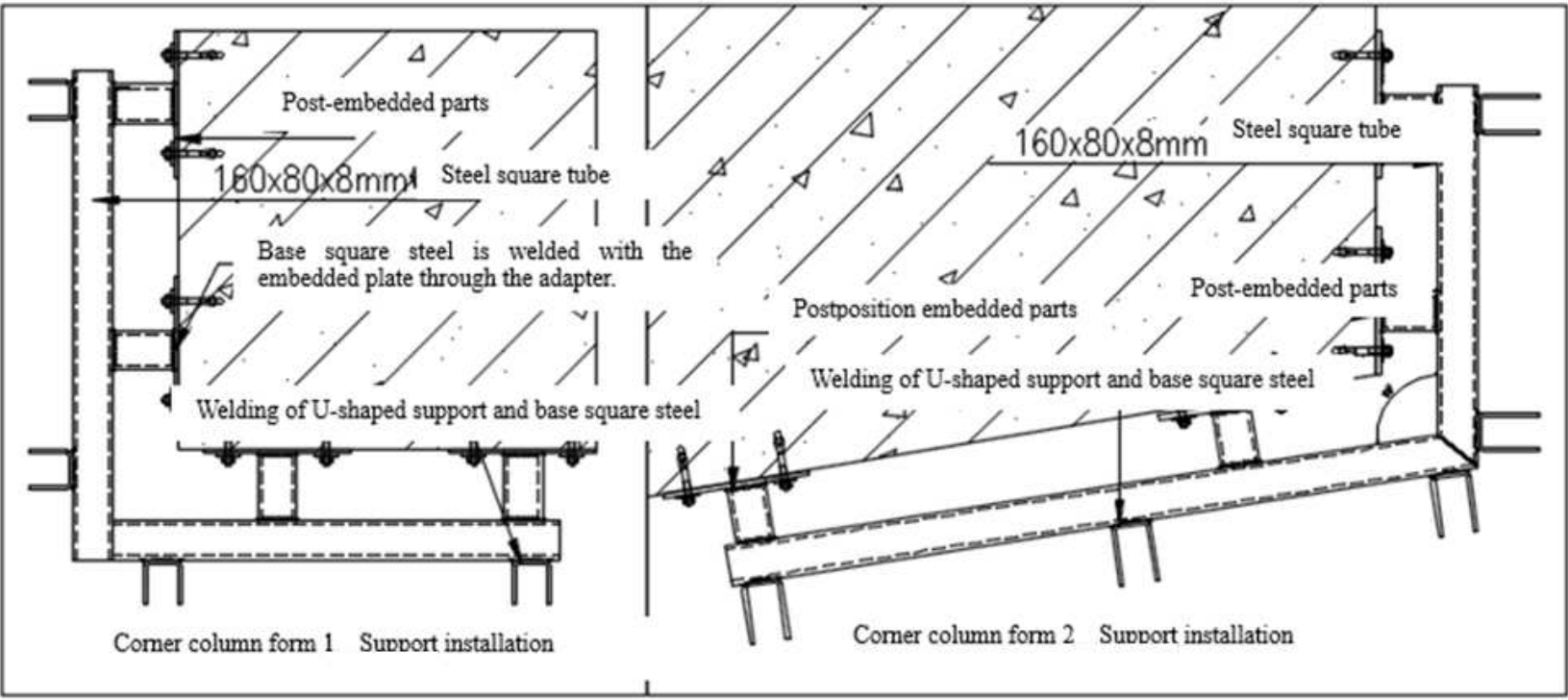

Figure 29. Support installation. 
Position control: pulled the vertical and horizontal through line, and selected the adapter with fit length according to the in and out position; first welded the unilateral adapter with the embedded part, checked the perpendicularity and in and out position, and reserved a $2 \mathrm{~mm}$ gap during positioning to guarantee the insertion of the construction members.

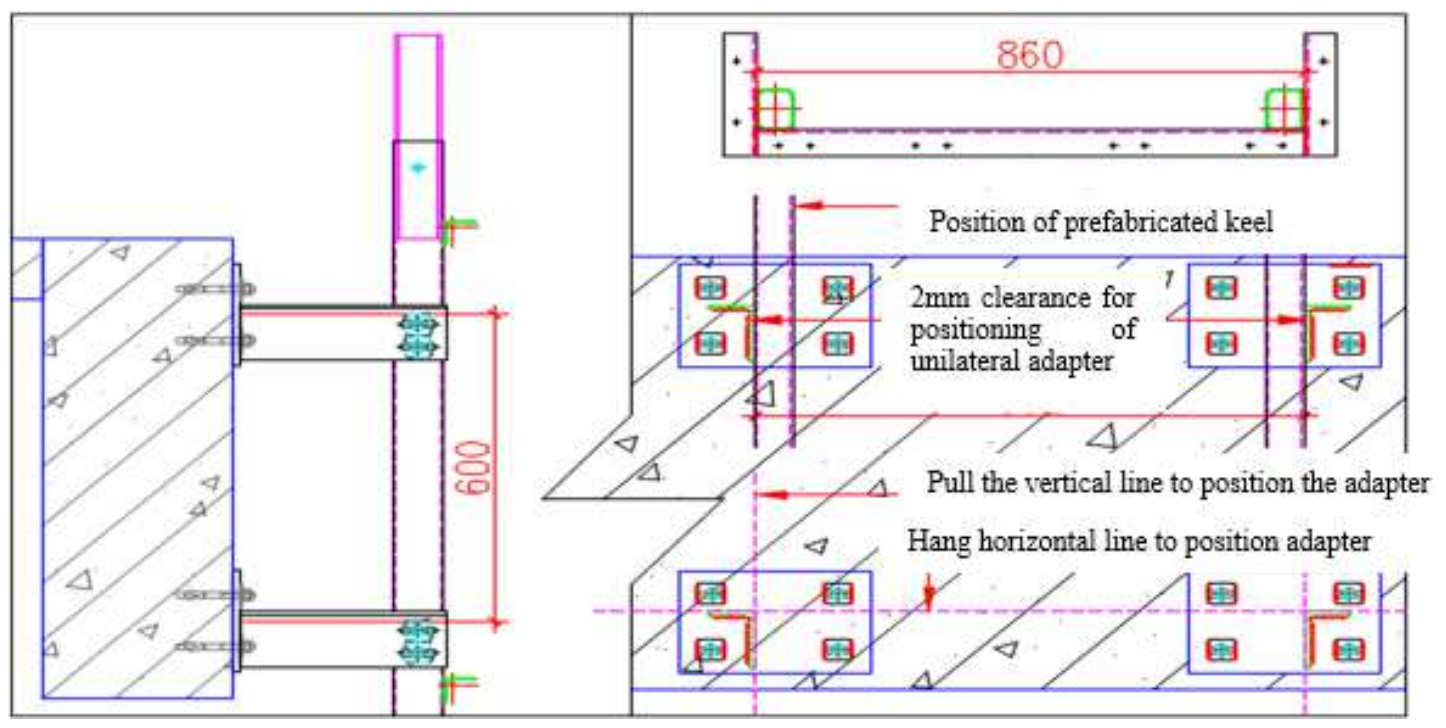

Figure 30. Position control.

Lifting:

Before installation, the ground was well protected and maintained by special personnel to prevent people from walking under the hoisting. The hanging basket was lifted to the installation position, the hoisting equipment steel cable was put down, manual hoist was installed on the steel cable for adjustment during installation, aviation straps were used to bind the prefabricated members firmly, prefabricated members were hung into the hoisting equipment hoist, and the safety buckles were locked; a traction rope was set at the lower end of the construction member, which was controlled by the personnel below to prevent collision with the structure which may damage the finished product during lifting and hoisting;

Adjustment of hoisting inclination of prefabricated base keel

It is proposed to use the winch placed on the roof. The assembled prefabricated base keel was lifted for a short distance, a rope clip hook was arranged on the hanging steel wire rope to make the manual hoist hang on the hanging steel wire rope, then workers slowly pulled the manual hoist to adjust the tilt angle of the fabricated keel until it was close to the required inclination.

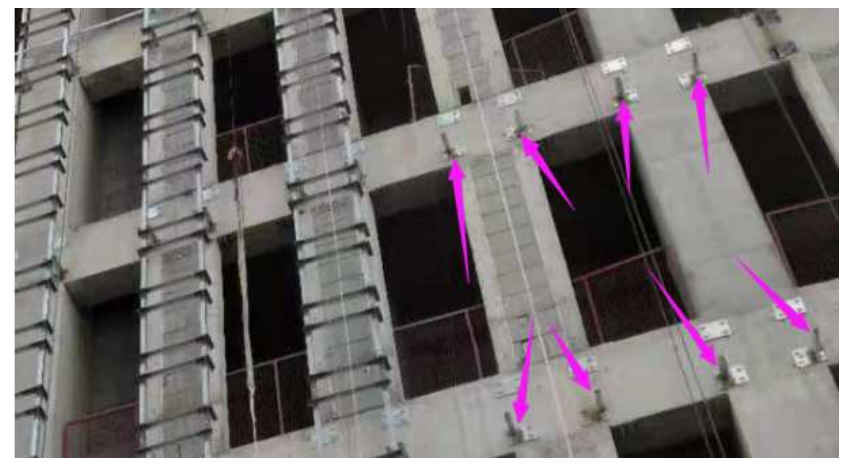

Figure 31. Construction site photos of Position control.
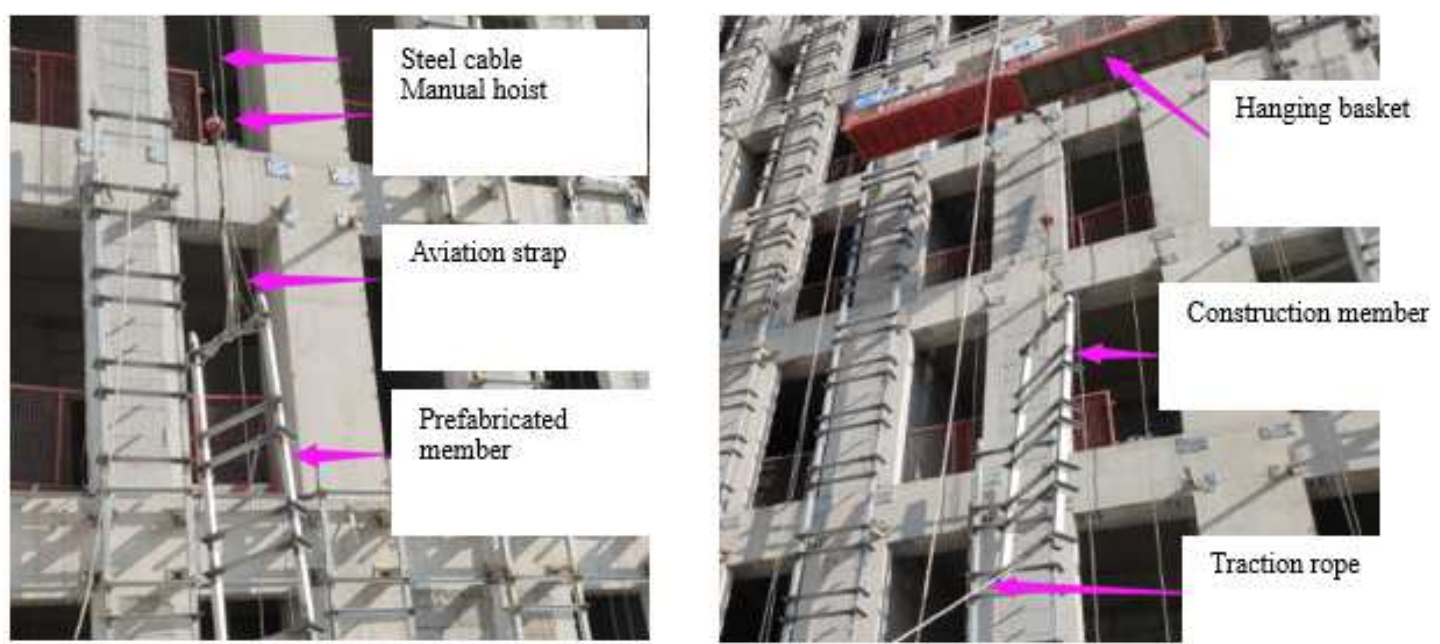

Figure 32. Lifting diagram (1). 


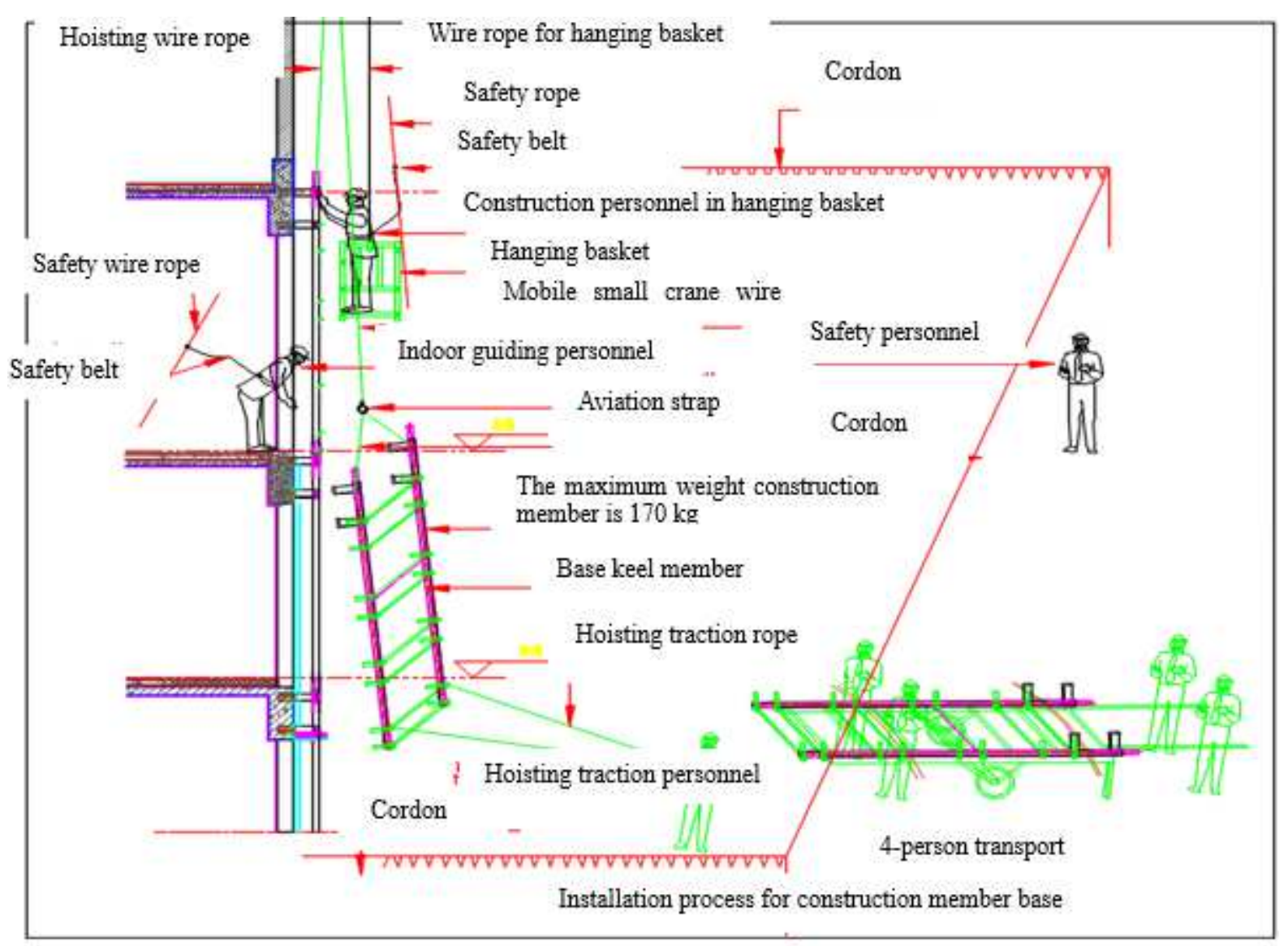

Figure 33. Lifting diagram (2).

After prefabricated members were at the installation position, manual hoist was used for adjustment, and the lower end of the component was inserted into the sleeve of the previous member. Then the upper part were clipped into the adapter, another adapter was installed and inserted with stainless steel bolts. After welding the adapter, the bolt was tightened;

Inspection and Acceptance of Welding Parts of Adapter

After the prefabricated hoisting was completed and full welding was completed, the welding slag was removed and the weld quality was inspected. According to the requirements, the single long side and short side of the weld should be full and free from defects such as missed welding, slag inclusion, undercut and bubble;

\subsubsection{Re-inspection}

After the anti-rust treatment was completed, the anti-rust treatment was inspected again, and the film measuring instrument was applied for spot check until the requirements were met; the anti-rust treatment should be horizontal and vertical, and the edge should be cleaned. The rust prevention should not be less than two times and the film thickness should not be less than $110 \mu \mathrm{m}$;

\subsubsection{Sealant Treatment at Expansion Joint}

A $20 \mathrm{~mm}$ expansion joint should be reserved between the previous member and the next member. After the above work was completed and qualified, sealant treatment was carried out;

\section{Quality Control of Prefabricated Base Keel}

Prefabricated Base Keel

(1) The surface of prefabricated base keel should be flat, clean, free of pollution and defects. The anti-rust coating should be obvious and the film thickness should meet the requirements. It was not allowed to drag soldering on the steel at will during assembly; the welding parts should meet the design requirements (including arc height and welding length); the processing specifications should meet the requirements of design and assembly drawings [13];

Test method: film tester and visual inspection.

(2) Processing quality of single construction member

The main keel of the project was $80 * 60 * 4 \mathrm{~mm}$ square steel tube, the sleeve was $70 * 50 * 4 \mathrm{~mm}$ square steel tube, and single side insert core can be adjusted to $2 \mathrm{~mm}$; the positive and negative deviation of distance between left and right side of the member as well as of the flatness should be less than 1 $\mathrm{mm}$; the adjustable range of stone back bolt aluminum alloy pendant should be $5 \mathrm{~mm}$, and the bending degree of steel square column should not be greater than $4 \mathrm{~mm}[14,15]$;

(3)The quality requirements of prefabricated base products of the project should meet the requirements of the following sheet: 
Table 1. The quality requirements of prefabricated base products of the project.

\begin{tabular}{llll}
\hline No. & Item & Quality requirement & Test method \\
\hline 1 & Front straightness & $\leqq 4 \mathrm{~mm}$ & Band pass measurement \\
2 & Side straightness & $\leqq 4 \mathrm{~mm}$ & Band pass measurement \\
3 & Square (diagonal) & $5 \mathrm{~mm}$ & Band tape \\
4 & Anti-rusting paint & $110 \mu \mathrm{m}$ & Film measuring instrument \\
\hline
\end{tabular}

(4) The installation quality of prefabricated base keel should meet the requirements of the following sheet:

Table 2. The installation quality of prefabricated base keel.

\begin{tabular}{lllll}
\hline No. & Item & & Allowable deviation & Test method \\
\hline & & Height of curtain wall $\leqq 30 \mathrm{~m}$ & $10 \mathrm{~mm}$ & Band pass measurement or \\
1 & Verticality & $30 \mathrm{~m}<$ Height of curtain wall $\leqq 60 \mathrm{~m}$ & $15 \mathrm{~mm}$ & theodolite \\
& & $60 \mathrm{~m}<$ Height of curtain wall $\leqq 90 \mathrm{~m}$ & $20 \mathrm{~mm}$ & Band pass measurement \\
\hline
\end{tabular}

\section{Conclusion}

For stone curtain wall keel of multi-functional building for office of Qinghai Rural Credit and Xining Rural Commercial Bank, prefabricated construction were adopted to avoid cross operation and reduce wall welding, and temporary road closure due to site construction lasted for a short period; no elevator was needed for material transportation, which provided more transportation time for other works; construction failure which may affect the construction period in rainy days were avoided; the construction time in hanging basket was shortened, the safety and quality were at better control, and work efficiency was improved; the selection of measures, construction progress, quality and safety were effectively guaranteed, the security risk and construction cost were reduced, and the economic benefits were improved;

\section{References}

[1] Hygrothermal system-performance of a whole building [J]. Achilles Karagiozis, Mikael Salonvaara. Building and Environment. 2001 (6).

[2] Release of Curtain Wall Standards and Overview of Curtain Wall Industry Development - Thoughts on Release of JG 3035 Standard and JGJ 102 Code for Ten Years [J]. Long Wenzhi. Shanghai Construction Science \& Technology. 2007 (S1).

[3] Discussion on Dry Hanging Technology of Stones for External Wall of Buildings [J]. Yin Chengliang, Zhang Yukun. Jiangsu Construction. 2006 (04).

[4] Stiffness considerations in dimension stone anchorage design. CONROY K, HOIGARD K R. Journal of ASTM International. 2007.
[5] Investigation of masonry failure of a granite and limestone clad historic church in eastern Pennsylvania. ERDLY J L, VALENTINO E R. Journal of ASTM International. 2007.

[6] Validation of an inspection and diagnosis system for anomalies in natural stone cladding (NSC) [J]. Natália Neto, Jorge de Brito. Construction and Building Materials. 2011.

[7] Slate flexural and anchorage strength considerations in cladding design [J]. Vera Pires, P. M. Amaral, L. G. Rosa, R. S. Camposinhos. Construction and Building Materials. 2011 (10).

[8] Undercut anchorage in dimension stone cladding. CAMPOSINHOS R S. Construction Materials. 2013.

[9] Dimension stone design - kerf anchorage in limestone and marble. Camposinhos, Rui S, Camposinhos, Rui Pedro A. Proceedings of Institution of Civil Engineers: Construction Materials. 2012.

[10] Research on Test and Evaluation Method of Bending Strength of Stones in Building Curtain Walls [J]. Chen Haokai, Liu Junjin, Li Jianhui, Liang Yundong. Building Science. 2015 (11).

[11] Comparative Analysis of Stone Strength Calculation in Stone Curtain Walls [J]. Chen Zhuning. New Technology and New Products of China. 2010 (06).

[12] Code for Construction Quality Acceptance of Building Decoration GB 50210-2018.

[13] Technical Code for Metal and Stone Curtain Walls Engineering JGJ 133-2001.

[14] Chen Jiang. Explore the Application of Prefabricated Construction Method of Curtain Wall in Engineering [J]. Theoretical Research. 2017 (25): 143-144.

[15] Construction Technology of Stone Curtain Wall in the Capital Museum [J]. Li Xuan. Sci-Tech Information Development \& Economy. 2008 (14). 